\title{
Triplication of the Photocurrent in Dye Solar Cells by Increasing the Elongation of the $\pi$ conjugation in Zn-Porphyrin Sensitizers
}

\author{
Eva M. Barea, ${ }^{*}{ }^{[a]}$ Rubén Caballero, ${ }^{[b]}$ Leticia López-Arroyo, ${ }^{[b]}$ Antonio Guerrero, ${ }^{[a]}$ \\ Pilar de la Cruz, ${ }^{[\mathrm{b}]}$ Fernando Langa, ${ }^{[\mathrm{b}]^{*}}$ and Juan Bisquert ${ }^{[\mathrm{a}]^{*}}$
}

Porphyrins are very promising sensitizers for dye solar cells (DSC) but narrow absorption bands at 400-450 and 500-650 $\mathrm{nm}$ limit their light-harvesting properties. Increasing elongation of the $\pi$ conjugation and loss of symmetry causes broadening and a red shift of the absorption bands, which considerably improves the performance of the DSC. In this work we use an oligothienylenevinylene to bridge a $Z n$-porphyrin system and the anchoring group of the sensitizer. We study separately the performance of the two basic units:

\section{Introduction}

Dye-sensitized solar cells (DSCs) have attracted significant attention as low-cost alternatives to conventional solid-state photovoltaic devices. In these cells, a nanoporous material is filled with a thin layer of a sensitizer which can be photoexcited to ultimately provide a photocurrent. ${ }^{1}$ Ruthenium-based dyes have been used as the most successful sensitizers to date yielding up to $11.3 \%$ solar-to-electric power conversion efficiencies under 1 sun ilumination. ${ }^{2,3}$ However, these dyes lack some of the desired properties required for their large scale production: low raw material costs and a good spectral matching with the solar radiation. Thus, there is real need for the development of inexpensive dyes with improved light absorption in the red and near infrared region. Extended $\pi$-aromatic molecules have the potential to fulfill these two requirements. ${ }^{4-9}$

Porphyrins are molecules that contain a heterocylic macrocycle with a $\pi$-aromatic core. These do not rely on precious metals such as ruthenium and benefit from very high molar extinction coefficients. Metaloporphyrins show an intense Soret band at $400-450 \mathrm{~nm}$ and moderate $Q$ bands at $500-650 \mathrm{~nm} .{ }^{10}$ Compared to the ruthenium complexes, these narrow bands limit the light-harvesting properties for porphyrins-based DSC. However, it has been demonstrated that elongation of the $\pi$ conjugation and loss of symmetry causes broadening and a red shift of the absorption bands in porphyrins. ${ }^{9,11,12}$ Additionally, they present good photostability and high light-harvesting capabilities that favour applications in thin low cost DSC. In this work we describe the impact of using an oligothienylenevinylene to bridge a Zn-porphyrin system and the anchoring group of the sensitizer. We show that this strategy increases the extended $\pi$ system producing an exceptional absorption enlargement between 450 oligothienylenevinylene and Zn-porphyrin. The combined system provides a 3-fold enhancement of the photocurrent with respect to parent dyes. This is caused by an additional strong absorption in the region $400-650 \mathrm{~nm}$ that leads to flat IPCE of $60 \%$. Theoretical calculations support that the addition of the oligothienylenevinylene unit as a linking bridge creates a charge transfer band that transforms a Zn-porphyrin dye into a push-pull type system with highly efficient charge injection properties.

and $650 \mathrm{~nm}$. This translates into a 3-fold photocurrent increase to reach a cell efficiency of $\eta=4.77 \%$.

\section{Results and Discussion}

A Zn-porphyrin sensitizer with extended absorption was synthesised by the structural combination of the Zn-porphyrin (1) and a previously reported dye containing two oligothienylenevinylene units (2). ${ }^{13}$ The structures of these sensitizers (including terminal groups for anchoring to $\mathrm{TiO}_{2}$ surface) are shown in Figure 1. Thus, the Zn-porphyrinoligothienylenevinylene (3) was designed having the main features of $\mathbf{1}$ and $\mathbf{2}$ linked by a styryl group. The porphyrins $\mathbf{1}$ and 3 dyes were prepared by Knoevenagel condensation of the corresponding aldehydes ${ }^{13}$ and cyanoacetic acid in $72 \%$ and $89 \%$ yield, respectively. The oligothienylenevinylene dye (2) was prepared according to a previously described procedure. ${ }^{13}$ Further details of synthesis methods are given in SI as well as full characterization data.

[a] E.M. Barea*, Antonio Guerrero, and Juan Bisquert* Photovoltaic and Optoelectronic Devices Group. Physics Department

Universitat Jaume I

12071 Castelló (Spain)

E-mail: barea@fca.uji.es; bisquert@fca.uji.es

[b] R. Caballero, L. López-Arroyo, P. de la Cruz, F. Langa* Instituto de Nanociencia, Nanotecnología y Materiales Moleculares (INAMOL)

Universidad de Castilla La Mancha

Campus de la Antigua Fábrica de Armas Avda. Carlos III, s/n 45071. Toledo (Spain).

E-mail: Fernando.LPuente@uclm.es

Supporting information for this article is available on the WWW under http://Www.chemphyschem.org or from the author 


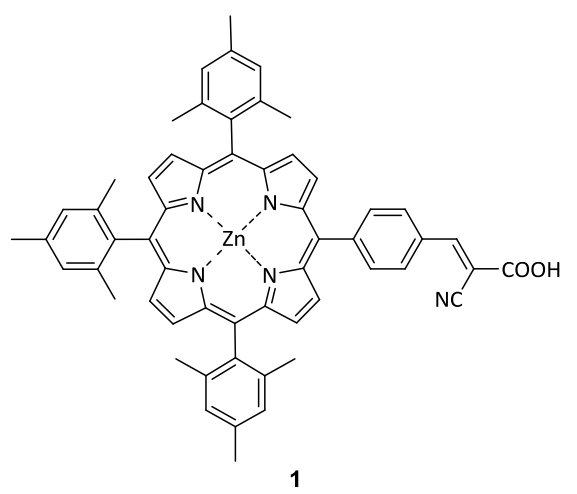

(1)

2

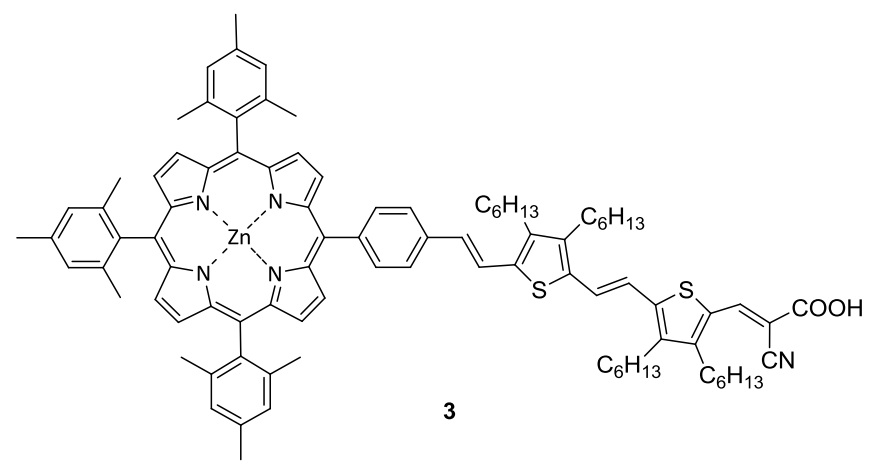

Figure 1. Structure of Zn-porphyrin dye (1), oligothienylenevinylene dye (2) and $\mathrm{Zn}$-porphyrin- oligothienylenevinylene dye (3).

The electrochemical properties (see SI) of the new dyes 1 and 3 were investigated by cyclic and OSWV voltammetries (vs. $\mathrm{Ag} / \mathrm{AgNO}_{3}$ in o-dichlorobenzene-acetonitrile (4:1) solution $(0.1$ mol dm${ }^{-3} \mathrm{Bu}_{4} \mathrm{NClO}_{4}$ ) and those of 2 were previously described. ${ }^{13}$ Both new dyes show reversible oxidation potentials at $0.40 \mathrm{~V}$ and $0.73 \mathrm{~V}$ (dye 1) and $0.33 \mathrm{~V}$ and $0.73 \mathrm{~V}$ (dye 3), in addition, dye 3 shows a non reversible oxidation potential at $0.53 \mathrm{~V}$ assigned to the oligothienylenevinylene bridge. ${ }^{13}$ The HOMO values (calculated with respect to ferrocene, HOMO:-4.8eV) were determined as $-5.01 \mathrm{eV}$ for dye $\mathbf{1}$ and $-5.03 \mathrm{eV}$ for dye $\mathbf{3}$. Thus, the introduction of the electroactive $\pi$-bridge should favour a cascade electron transfer process increasing the lifetime of the charge separated state by slowing down the charge recombination process.

UV-vis spectra of dyes $\mathbf{1}$ and $\mathbf{3}$ in solution of dichloromethane are shown in Figure 2. Dye 1 shows the typical absorption spectra of a porphyrin moiety with bands at $422 \mathrm{~nm}$ ( $\log \varepsilon=5.4$, Soret band) and $551 \mathrm{~nm}$ and $594 \mathrm{~nm}(\log \varepsilon=4.4$ and 4.2 respectively, $Q$ bands). In addition to the $Q$ band, dye 3 shows broader and increased intensity absorption between 430 $\mathrm{nm}$ and $630 \mathrm{~nm}$ due to presence of the oligothienylenevinylene $\pi$ system, with maximum at $552 \mathrm{~nm}(\log \varepsilon=4.72) .{ }^{13}$

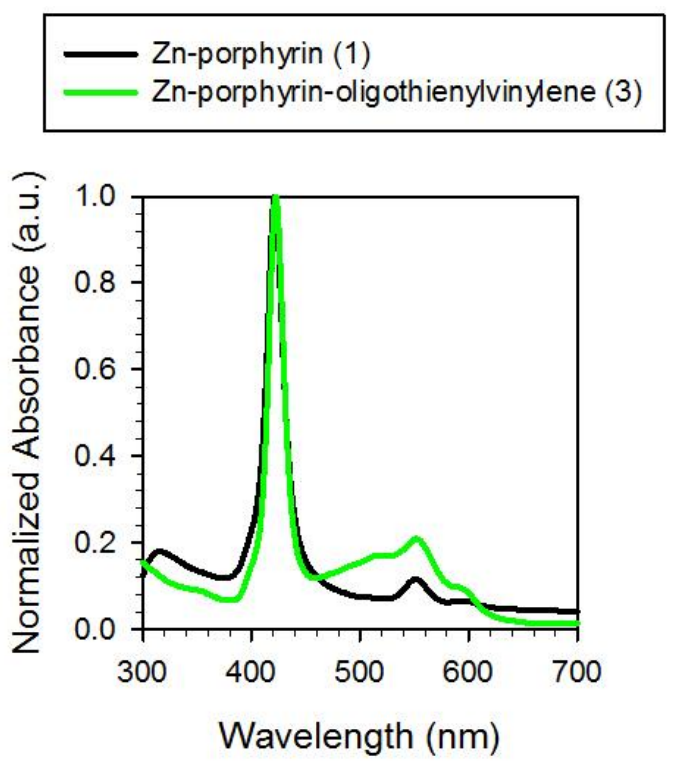

Figure 2. Normalized UV-vis spectra in dichloromethane solution of dyes 1 and

Figure 3 shows the steady-state fluorescence spectra in dichloromethane of dye $\mathbf{3}$ (solid line) and the same dye containing $\mathrm{TiO}_{2}$ attached to the carboxylic acid group (dotted line). By excitation at $422 \mathrm{~nm}$ (Soret band of the Zn-porphyrin) in the absence of $\mathrm{TiO}_{2}$ the spectra shows photoluminescence of the $1 \mathrm{ZnP}{ }^{*}$ moiety (maxima at 606 and $650 \mathrm{~nm}$ ). On the other hand, in the presence of $\mathrm{TiO}_{2}$ the fluorescence intensity was significantly reduced to provide nearly quantitative quenching. This fluorescence quenching can be attributed to the photoinduced electron transfer process from Zn-Porphyrin to the $\mathrm{TiO}_{2}$ surface, favored by the efficiency of oligothienylenevinylene acting as a wire between donors and acceptors. ${ }^{13}$ Similar fluorescence effect is observed for dye $\mathbf{1}$ in the presence of $\mathrm{TiO}_{2}$ (see Supporting Information), exciting at the same wavelength (Soret band of the Porphyrin). However, only partial quenching is observed for dye 2 excited at $488 \mathrm{~nm}$. These results are very interesting as in the operating DSC the dye 3 is attached to the $\mathrm{TiO}_{2}$ through a oligothienylenevinylene unit which itself does not show so good charge transfer properties for dye $\mathbf{2}$. Thus, the porphyrin moiety is determining the charge transfer and injection properties for dye $\mathbf{3}$.

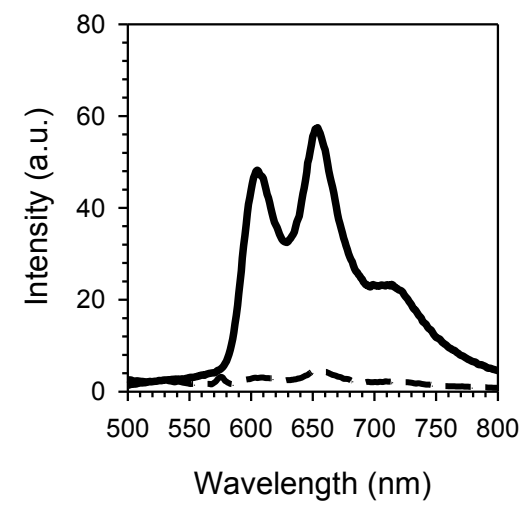

Figure 3. Emission spectra of dye 3 (dichloromethane, $\lambda_{\mathrm{exc}}=422 \mathrm{~nm}$ ) in absence(solid line) and presence (dotted line) of $\mathrm{TiO}_{2}$. 
Density Functional Theory (DFT) is known to be a powerful tool to elucidate the fundamental electronic processes taking place during light absorption and charge transport. ${ }^{14}$ Here, the geometries of the dyes 1, 2 and 3 were optimised at the B3LYP/6-31G $\left({ }^{*}\right.$ ) level of theory using Gaussian 03 (see SI for details). Optimized geometry of oligothienylenevinylene dye adopts a planar conformation with both highest occupied molecular orbital (HOMO) and lowest unoccupied molecular orbital (LUMO) delocalized along the total extent of the conjugated backbone (Figure 4). These are primarily comprised of the $\pi$ framework of the thiophene, vinylidene, cyano and anchoring groups. Alternatively, Zn-porphyrin presents a conformation with a planar porphyrin moiety with three perpendicular trimethylbenzenes and one aryl ring linked with the porphyrin. Whilst the HOMO is localized in the porphyrin ring the LUMO is mainly delocalized in the region of the anchoring group with a small contribution in the porphyrin ring. Finally, the optimized geometry of dye $\mathbf{3}$ is similar to the Zn-porphyrin $\mathbf{1}$ around the porphyrin unit and as planar as oligothienylenevinylene dye in its analogous part. The HOMO is delocalized in the porphyrin and thiophene vinylidene groups with a small contribution of the phenyl and anchoring group. On the other hand, the LUMO is well localized in thiophene vinylidene and anchoring groups with no contribution of the porphyrin moiety. In this last dye, the total split of $\pi$ and $\pi^{*}$ orbitals in the porphyrin core enhances charge transfer and charge separation processes. Calculated energy values for HOMO and LUMO and Eg (LUMOHOMO) are shown in Table 1 . These results clearly reveal a decrease in the Eg from the parent dyes to the Zn-porphyrinoligothienylenevinylene that explains the red shift in the absorption band.

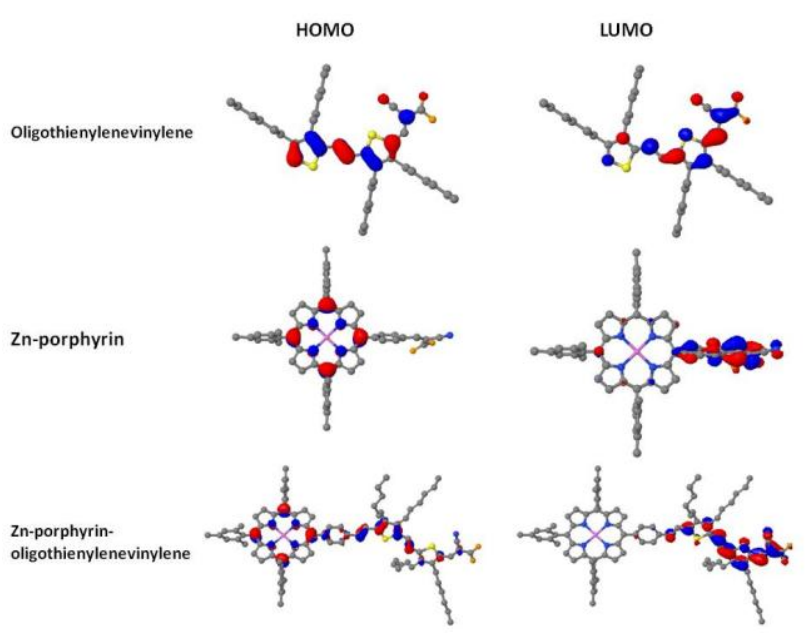

Figure 4. Optimized geometries of Zn-porphyrin (1), oligothienylenevinylene (2), and Zn-porphyrin- oligothienylenevinylene (3) dyes with HOMO (Left) and LUMO (Right) orbitals. The surfaces have been generated with an isovalue at 0.035 and hydrogen atoms have been omitted for clarity.

\begin{tabular}{|c|c|c|c|}
\hline \multirow{2}{*}{$\begin{array}{l}\text { Table 1. Calculated HOMO and } \\
\text { oligothienylenevinylene, } \\
\text { oligothienylenevinylene dyes }\end{array}$} & $\begin{array}{l}\text { JMO If } \\
\text { anc }\end{array}$ & \multicolumn{2}{|c|}{$\begin{array}{l}\text { and } \mathrm{Eg} \text { of } \\
\text { Zn-porphyrin- }\end{array}$} \\
\hline & $\begin{array}{l}\text { HOMO } \\
(\mathrm{eV})\end{array}$ & $\begin{array}{l}\text { LUMO } \\
(\mathrm{eV})\end{array}$ & $\begin{array}{l}\mathrm{Eg}^{[\mathrm{a}]} \\
(\mathrm{eV})\end{array}$ \\
\hline Zn-porphyrin (1) & -5.23 & -2.62 & 2.61 \\
\hline Oligothienylenevinylene (2) & -5.29 & -2.62 & 2.67 \\
\hline Zn-porphyrin-oligothienylenevinylene (3) & -5.01 & -2.83 & 2.18 \\
\hline
\end{tabular}

[a] Eg = LUMO-HOMO
Figure 5 shows the film absorption spectra of the three dyes under study and N719 as reference dye, all the spectra were taken under the same conditions $(0.3 \mathrm{mM}$ dye solution, 2 hour absorption time). Both parent dyes $\mathbf{1}$ and $\mathbf{2}$, show a band with a $\lambda_{\max }$ at approximately $420 \mathrm{~nm}$, additionally, the Zn-porphyrin dye confirms the typical $Q$ band at $580 \mathrm{~nm}$. The addition of two thienylenevinylene units to the Zn-porphyrin provides a new absorption area between 450 and $650 \mathrm{~nm}$ for the sensitizer 3 , due to the elongation of the $\pi$ conjugated system that splits the $\pi$ and $\pi^{*}$ levels in the porphyrin gap between the HOMO and the LUMO. Thus, this structural change leads to broadening and red shift of the absorption bands together with an increased intensity especially that of the $Q$ bands relative to the Soret band.
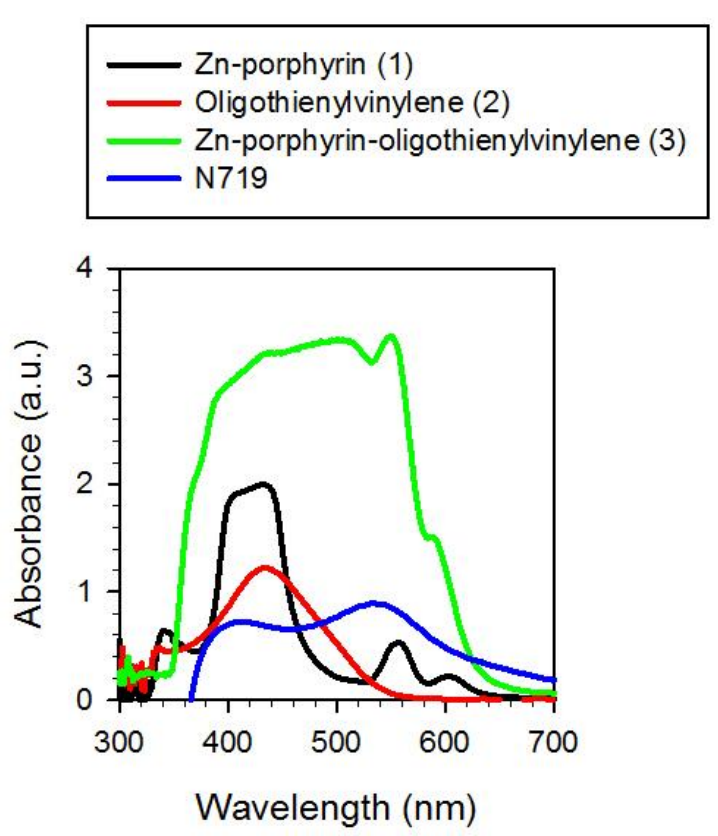

Figure 5. UV-vis spectra for Zn-porphyrin (1), oligothienylenevinylene (2), Znporphyrin- oligothienylenevinylene (3) and N719 dyes attached on transparent $\mathrm{TiO}_{2}$ films

By the integration of the absorption spectra of Figure 5 with the solar spectrum, it is possible to calculate the maximum current that we can obtain from each dye, without any contribution like recombination or regeneration process that could take place during the DSC performance. For parent's dyes, 1 and 2, the maximum current that we can get is 11.8 and $11 \mathrm{~mA} / \mathrm{cm}^{2}$ respectively, and for the new dye 3 the maximum current is 18.2 $\mathrm{mA} / \mathrm{cm}^{2}$ that will be translate to a higher overall conversion efficiency due to a push-pull type system generated by the addition of the oligothienylenevinylene unit added to dye 1. In the case of N719 dye, the current that we can get is very low due to experimental conditions used for measured the UV-vis spectra and that is reflected in the overall conversion efficiency of the N719 DSC.

From that calculation is clearly observed that both, absorption and injection, contribute to the incident photon-tocurrent efficiencies (IPCE) reported in Figure 6. The addition of the oligothienylenevinylene unit as a linking bridge through a styryl group for dye $\mathbf{3}$ transforms a Zn-porphyrin dye into a pushpull type system. Thus, the enormous gain in the absorption of the film between 450 and $600 \mathrm{~nm}$ observed for $\mathrm{Zn}$-porphyrinoligothienylenevinylene is also reflected in the IPCE results. This leads to an IPCE of $60 \%$ for Zn-porphyrin-oligothienylenevinylene that remains flat between 400 and $650 \mathrm{~nm}$. Finally, it is important to note that IPCE results for dye $\mathbf{3}$ are similar to those obtained 
for a DSC sensitized with standard N719 dye fabricated under the same conditions.

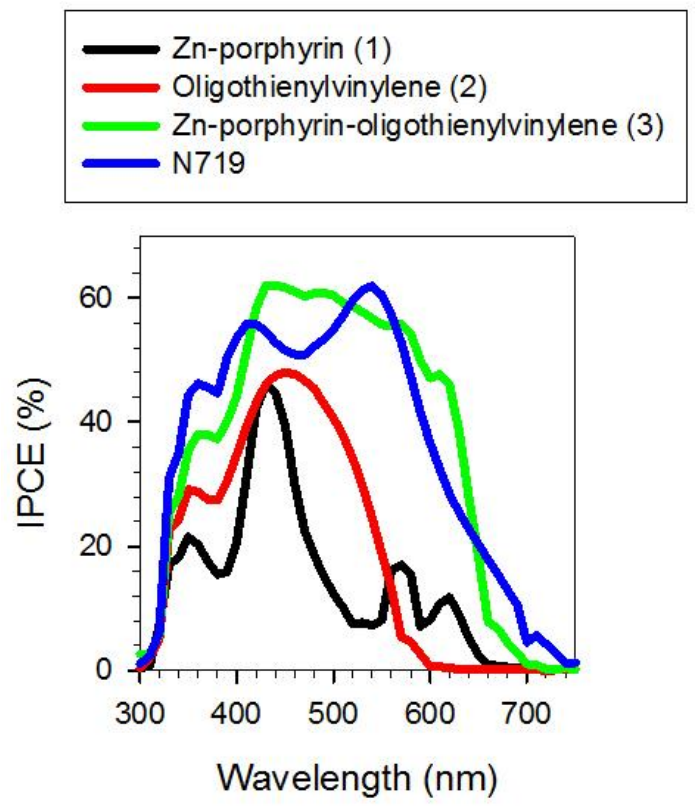

Figure 6. The incident photon-to-current efficiencies (IPCE) for Zn-porphyrin (1), oligothienylenevinylene (2), Zn-porphyrin- oligothienylenevinylene (3) and N719 dyes.

The performance of DSC based on Zn-porphyrines ( 1 and 3), oligothienylenevinylene (2) and N719 under 1 sun illumination, is shown in Table 2 and Figure 7 . It is important to note that results obtained for all dyes have been obtained using relatively thin layers of nanoporous $\mathrm{TiO}_{2}(6 \mu \mathrm{m})$. Lower than previously reported efficiencies obtained for N719 are expected as a reflection of the fabrication conditions: (1) relatively short time deep in dye solution (2 hours) combined with low absorption coefficient of the Ruthenium sensitizer and (2) the electrolyte composition without ionic liquid. In this work, both Zn-porphyrin 1 and oligothienylenevinylene 2, provide a modest overall conversion efficiency that remains below $2 \%$. Compared with the parent dyes, the Zn-porphyrin-oligothienylenevinylene presents an increment in the photocurrent of around $300 \%$ and a $100 \mathrm{mV}$ higher open-circuit voltage, producing a large increment of the overall solar cell performance to $4.77 \%$.

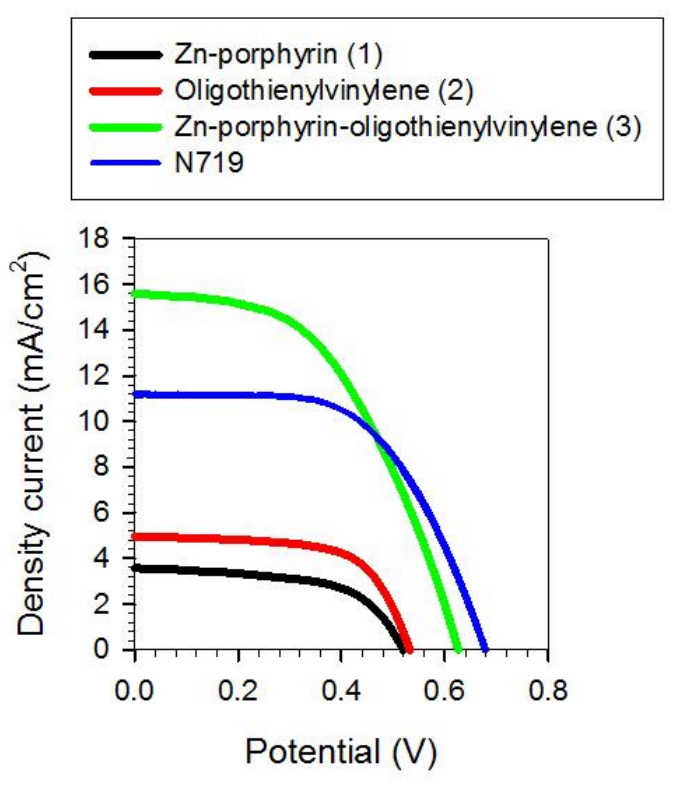

Figure 7. $j-V$ curves of DSCs sensitized with Zn-porphyrin (1), oligothienylenevinylene (2), Zn-porphyrin- oligothienylenevinylene (3) and N719 dyes under standard conditions $\left(100 \mathrm{mWcm}^{-2}, \mathrm{AM} 1.5\right)$.

Table 2. Performance of the DSC devices based on the different sensitizers at 1 sun

\begin{tabular}{|c|c|c|c|c|}
\hline Sensitizer molecule & $\begin{array}{l}\mathrm{V}_{\mathrm{oc}}^{[\mathrm{a}]} \\
(\mathrm{V})\end{array}$ & $\begin{array}{l}\mathrm{j}_{\mathrm{sc}}[\mathrm{b}] \\
\left(\mathrm{mA} / \mathrm{cm}^{2}\right)\end{array}$ & $\mathrm{FF}^{[\mathrm{c}]}$ & $\begin{array}{l}\eta^{[\mathrm{d}]} \\
(\%)\end{array}$ \\
\hline Zn-porphyrin (1) & 0.52 & 3.6 & 0.58 & 1.10 \\
\hline Oligothienylenevinylene (2) & 0.53 & 5.0 & 0.64 & 1.74 \\
\hline $\begin{array}{l}\text { Zn-porphyrin- } \\
\text { oligothienylenevinylene ( } 3 \text { ) }\end{array}$ & 0.62 & 15.6 & 0.49 & 4.77 \\
\hline N719 & 0.67 & 11.1 & 0.57 & 4.27 \\
\hline
\end{tabular}

[a] $V_{o c}$ is open circuit potential [b] $j_{s c}$ is the short circuit current [c] FF is the fill factor and $\eta$ is the conversion efficiency at 1 sun.

\section{Conclusion}

In conclusion, we showed that the strategy based on elongation of the $\pi$ conjugation and loss of symmetry in porphyrins produces an enhancement in both the short circuit photocurrent and opencircuit potential, due to an important increase in the light absorption and improved charge injection in the DSC. Thus, the performance of both $\mathrm{Zn}$ - porphyrin and oligothienylenevinylene dyes has been improved significantly from $1.10 \%$ and $1.74 \%$, respectively, by using a combination of their structures to $\eta=$ $4.77 \%$, obtaining similar efficiency to N719 dye under the same DSC fabrication conditions. PL measurements prove that good electron transfer takes place for the improved porphyrin (dye 3) system that enables good electron injection into the $\mathrm{TiO}_{2}$. Alternatively, theoretical study by DFT supports an enhancement in the light absorption. This improvement is obtained by the increase in the conjugation of the $\pi$ system that reduces the $E_{g}$ red shifting the absorption and gives rise to a charge transfer state by completely removing the participation of the porphyrin system in the LUMO of the molecule. Both of these aspects contribute to an increased IPCE and higher overall energy conversion efficiency. 


\section{Experimental Section}

Dye Solar Cells (DSC) were prepared using $\mathrm{TiO}_{2}$ nanocrystalline paste $\left(50 \mathrm{~nm}\right.$ particle size from Dyesol). The $\mathrm{TiO}_{2}$ layers were deposited with Doctor Blading technique on Transparent Conducting Oxide (TCO) glass (Pilkington TEC15, $15 \Omega /$ sq resistance). The resulting photoelectrodes of $6 \mu \mathrm{m}$ thickness, were sintered at $450^{\circ} \mathrm{C}$ and then immersed in $0.04 \mathrm{M} \mathrm{TiCl}_{4}$ solution for $30 \mathrm{~min}$ at $70^{\circ} \mathrm{C}$ followed by calcination at 450 for 30 min to obtain good electrical contact between the nano-particles. When the temperature decreased to $40^{\circ} \mathrm{C}$ all the electrodes were immersed into dye solution $(0.3 \mathrm{mM}$ in dicloromethane and $0.3 \mathrm{mM}$ acetonitrile/ tert-butanol for N719) for 2 hours. After the adsorption of the dye, the electrodes were rinsed with the same solvent. The solar cells were assembled with counter electrode (thermally platinized TCO) using a thermoplastic frame (Surlyn $25 \mu \mathrm{m}$ thick). Redox electrolyte (0.5M Lil $(99,9 \%), 0.05 \mathrm{M} \mathrm{I}_{2}$ $(99,9 \%)$ and $0.5 \mathrm{M}$ 4-tertbutilpyridine in 3-methoxypropionitrile) was introduced through a hole drilled in the counter electrode that was sealed afterwards. Prepared solar cells $\left(0.4 \mathrm{~cm}^{2}\right.$ size, masking solar cell to $0.25 \mathrm{~cm}^{2}$ ) were characterized by thin film absorption measurements, current-voltage characteristics and incident photon to current efficiency (IPCE). UV-Vis data was obtained using a Cary 300 Bio Spectrophotometer with the adequate set up for thin film analysis. Photocurrent and voltage were measured using a solar simulator equipped with a $1000 \mathrm{~W}$ ozone-free Xenon lamp and AM $1.5 \mathrm{G}$ filter (Oriel), were the light intensity was adjusted with an NREL-calibrated Si solar cell with a KG-5 filter to 1 sunlight intensity $\left(100 \mathrm{mWcm}^{-2}\right)$ and a $250 \mathrm{~W}$ Xenon arc lamp (Oriel) served as a light source for IPCE.

\section{Acknowledgements}

We thank financial support from Ministerio de Cíencia e Innovación under Projects HOPE CSD2007-00007 and CTQ2007-63363/PPQ, JJCC de Castilla-La Mancha (Project PCI08-038), Project ORION FP7-NMP-2008-LARGE-2 and Generalitat Valenciana under Project PROMETEO/2009/058
1. O' Regan, B.; Grätzel, M., A low-cost high-efficiency solar cell based on dye-sensitized colloidal TiO2 films. Nature 1991, 353, 737-740.

2. Nazeeruddin, M. K.; De Angelis, F.; Fantacci, S.; Selloni, A.; Viscardi, G.; Liska, P.; Ito, S.; Bessho, T.; Gratzel, M., J. Am. Chem. Soc. 2005, 127, 1683516847.

3. Gao, F.; Wang, Y.; Shi, D.; Zhang, J.; Wang, M.; Jing, X.; HumphryBaker, R.; Wang, P.; Zakeeruddin, S. M.; Gratzel, M., Journal of the American Chemical Society. 2008, 130, 10720-10728.

4. Hayashi, S.; Matsubara, Y.; Eu, S.; Hayashi, H.; Umeyama, T.; Matano, Y.; Imahori, H., Chem. Lett 2008, 37, 846-847.

5. Hayashi, S.; Tanaka, M.; Hayashi, H.; Eu, S.; Umeyama, T.; Matano, Y.; Araki, Y.; Imahori, H., J.Phys. Chem. C 2008, 112, 15576-15585.

6. Wang, Q.; Campbell, W. M.; Bonfantani, E. E.; Jolley, K. W.; Officer, D. L.; Walsh, P. J.; Gordon, K.; Humphry-Baker, R.; Nazeeruddin, M. K.; Gratzel, M., J. Phys. Chem. B 2005, 109, 15397-15409.

7. Campbell, W. M.; Jolley, K. W.; Wagner, P.; Wagner, K.; Walsh, P. J.; Gordon, K. C.; Lukas, S.-M.; Nazeeruddin, M. K.; Wang, Q.; Gratzel, M.; Officer, D. L., J. Phys. Chem. C 2007, 111, 11760-11762.

8. Tachibana, Y.; Haque, S. A.; Mercer, I. P.; Durrant, J. R.; Klug, D. R., J. Phys. Chem. B 2000, 104, 1198-1205.

9. Lu, H.-P.; Tsai, C.-Y.; Yen, W.-N.; Hsieh, C.-P.; Lee, C.-W.; Yeh, C.-Y.; Wei-Guang Diau, E., J. . Phys. Chem. C 2009, 113, 20990-20997.

10. Imahori, H.; Umeyama, T.; Ito, S., Accounts of Chemical Research 2009, 42, (11), 1809-1818.

11. Lee, C. Y.; Hupp, J. T., Langmuir, 2010, 26(5), 3760-3765.

12. Wu, S.-L.; Lu, H.-P.; Yu, H.-T.; Chuang, S.-H.; Chiu, C.-L.; Lee, C.-W.; Diau, E.; Yeh, C.-Y., Energy Environ. Sci. 2010, 3, 949-955.

13. Barea, E. M.; Caballero, R.; Fabregat.-Santiago, F.; de la Cruz, P.; Langa, F.; Bisquert, J., ChemPhysChem 2009, 11, 245.

14. Qin, P.; Linder, M.; Brinck, T.; Boschloo, G.; Hagfeldt, A.; Sun, L., Adv. Mater. 2009, 21, 2993-2996.

Received: ((will be filled in by the editorial staff)) Published online: ((will be filled in by the editorial staff))

Keywords: DSSC, Zn-porphyrin, push-pull 
Entry for the Table of Contents(Please choose one layout)

Layout 1:

\section{ARTICLES}

A new Zn-porphyrin sensitizer bridged with a oligothienylenevinylene unit shows a 3-fold enhancement of the photocurrent with respect to the parent dyes. This is caused by an additional strong absorption in the region $400-650 \mathrm{~nm}$ that leads to flat IPCE of $60 \%$ in this region. PL measurements and DFT calculations, respectively, suggest that increased injection and red shift of the absorption bands are the reason for an improved cell performance.

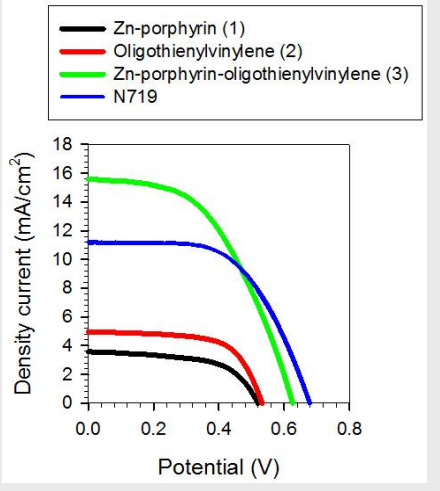

Eva M. Barea, Rubén Caballero, Leticia López-Arroyo, Antonio Guerrero, Pilar de la Cruz, Fernando Langa, ${ }^{*}$ and Juan Bisquert*

Page No. - Page No.

Triplication of the Photocurrent in Dye Solar Cells by Increasing the Elongation of the $\pi$ conjugation in Zn-Porphyrin Sensitizers 


\section{Triplication of the Photocurrent in Dye Solar Cells by Increasing the Elongation of the $\pi$ conjugation in Zn-Porphyrin Sensitizers}

\section{Eva M. Barea ${ }^{a^{\star}}$, Rubén Caballero ${ }^{b}$, Leticia López-Arroyo, ${ }^{b}$ Antonio Guerrero, ${ }^{a}$ Pilar de la Cruz $^{b}$, Fernando Langa $^{b^{*}}$ and Juan Bisquert. ${ }^{a^{*}}$}

${ }^{a}$ Photovoltaic and Optoelectronic Devices Group. Physics Department. Universitat Jaume I. 12071 Castelló (Spain)

b Instituto de Nanociencia, Nanotecnología y Materiales Moleculares (INAMOL). Universidad de Castilla La Mancha. Campus de la Antigua Fábrica de Armas, Avda. Carlos III, s/n 45071. Toledo (Spain)

Corresponding authors email:

barea@fca.uji.es, Fernando.Langa@uclm.es bisquert@fca.uji.es

\section{General}

NMR spectra were recorded as $\mathrm{CDCl}_{3}$ solutions on a Brüker-Topspin AV 400 instrument using tetramethylsilane (TMS) as an internal standard. Chemical shifts are given as $\delta$ values. Residual solvent peaks being used as the internal standard $\left(\mathrm{CHCl}_{3} ; \delta=7.27 \mathrm{ppm}\right)$. Electrochemical Measurement. were performed by cyclic and OSWVvoltammetry with a potentiostat BAS CV50W in a conventional threeelectrode cell equipped with Pt-working and counter electrodes with an $\mathrm{Ag} / \mathrm{AgCl}$ reference electrode at scan rate of $100 \mathrm{mV} / \mathrm{s}$. In each case, a solution containing $0.2 \mathrm{mM}$ of a sample with $0.05 \mathrm{M}$ of $n$ $\mathrm{Bu}_{4} \mathrm{NClO}_{4}$ (Fluka purest quality) was deaerated with argon bubbling before measurements. Steady-state absorption spectra were obtained on a Shimadzu UV 3600 spectrophotometer. Steady-state fluorescence spectra were measured on a Varian Cary-Eclipse. MALDI-TOF Mass spectra were obtained on a Vogaver DE STR using ditranol as matrix.

\section{Synthesis and Characterization Data}

\section{General Synthetic Procedure for Knoevenagel Reaction}

Under Ar, over a stirred solution of the corresponding aldehyde and cyanoacetic acid in $\mathrm{CHCl}_{3}, 2$ drops of piperidine are added and the mixture is refluxed for the indicated time. The solvent is evaporated under reduced pressure and the obtained product is purified by column chromatography (silica-gel, $\mathrm{CHCl}_{3}: \mathrm{MeOH}$ 9:1).

Dye 1. From $\mathrm{ZnP}_{-} \mathrm{CHO}^{1}$ (30. mg, $\left.0.036 \mathrm{mmol}\right)$, cyanoacetic acid (18 mg, $\left.0.214 \mathrm{mmol}\right)$. Reaction time: 17 h. Yield:72\% (23 mg). ${ }^{1} \mathrm{H}-\mathrm{NMR}\left(400 \mathrm{MHz}, \mathrm{CD}_{2} \mathrm{Cl}_{2}\right) \delta / \mathrm{ppm}: 8.83(\mathrm{~d}, 2 \mathrm{H}, J=5 \mathrm{~Hz}), 8.81(\mathrm{~d}, 2 \mathrm{H}, J=5 \mathrm{~Hz})$, $8.73(\mathrm{~s}, 4 \mathrm{H}), 8.67(\mathrm{~s}, 1 \mathrm{H}), 8.42(\mathrm{dd}, 4 \mathrm{H}), 7.28(\mathrm{~s}, 6 \mathrm{H}), 2.94(\mathrm{~s}, 3 \mathrm{H}), 2.82(\mathrm{~s}, 3 \mathrm{H}), 2.64(\mathrm{~s}, 21 \mathrm{H}) \quad{ }^{13} \mathrm{C}-\mathrm{NMR}$ $\left(100 \mathrm{~Hz}, \mathrm{CDCl}_{3}\right) \delta / \mathrm{ppm}: 150.0,149.9,149.7 .149 .2,148.7,139.1,139.1,138.9,137.9,137.5,135.4,135.1$,

\footnotetext{
${ }^{1}$ S. Islam, F. Oswald, Y. Araki, V. Troiani, R. Caballero, P. De La Cruz, O. Ito, F. Langa, Chem. Commun. 2007, 4498-4500.
} 
131.6, 131.1, 131.0, 130.8, 130.6,129.4, 128.9, 128.1, 127.6, 125.2, 125.0, 119.0, 118.1,21.43, 21.36, 21.14. UV-Vis $\left(\mathrm{CH}_{2} \mathrm{Cl}_{2}\right), \lambda_{\max }(\mathrm{nm})(\log \varepsilon)$ : 422 (5.42), 551 (4.47), 594 (4.23). EM ( $\left.m / z\right)$ (MALDI-TOF): calculated for $\mathrm{C}_{57} \mathrm{H}_{47} \mathrm{~N}_{5} \mathrm{O}_{2} \mathrm{Zn}$ : 897. 30; Found: $897.45(\mathrm{M}+1)$.

Dye 2.This dye was prepared according to the described procedure. ${ }^{2}$

Dye 3. From $\mathrm{ZnP}-2 \mathrm{TV}_{-} \mathrm{CHO}^{1}$ (61 mg, $0.04 \mathrm{mmol}$ ), cyanoacetic acid (6 mg, $\left.0.07 \mathrm{mmol}\right), 10 \mathrm{~mL}$ of $\mathrm{CHCl}_{3}$. Reaction time: 20 h. Yield: 89\% (57 mg). ${ }^{1} \mathrm{H}-\mathrm{NMR}\left(400 \mathrm{MHz}, \mathrm{CDCl}_{3}\right) \delta / \mathrm{ppm}: 8.93\left(\mathrm{~d}, 2 \mathrm{H},{ }^{3} \mathcal{J}=4.1 \mathrm{~Hz}\right)$, $8.77\left(\mathrm{~d}, 2 \mathrm{H},{ }^{3}=4.1 \mathrm{~Hz}\right), 8.71(\mathrm{~s}, 4 \mathrm{H}), 8.44$ (bs, 1H), 8.23 (d, 2H, $\left.{ }^{3} \mathrm{~J}=7.6 \mathrm{~Hz}\right), 7.86$ (d, 2H, ${ }^{3}$ =7.6 Hz), 7.57 $\left(\mathrm{d}, 1 \mathrm{H},{ }^{3}=16.0 \mathrm{~Hz}\right), 7.36\left(\mathrm{~d}, 1 \mathrm{H},{ }^{3}=15.2 \mathrm{~Hz}\right), 7.28(\mathrm{~m}, 7 \mathrm{H}(6 \mathrm{H}+1 \mathrm{H})), 7.12\left(\mathrm{~d}, 1 \mathrm{H},{ }^{3}=15.2 \mathrm{~Hz}\right), 3.07(\mathrm{~m}$, 2H), $2.73(\mathrm{~m}, 6 \mathrm{H}), 2.64(\mathrm{~s}, 9 \mathrm{H}), 1.85(\mathrm{~s}, 18 \mathrm{H}), 1.71-1.30(\mathrm{~m}, 32 \mathrm{H}), 1.03-0.82(\mathrm{~m}, 12 \mathrm{H}) .{ }^{13} \mathrm{C}-\mathrm{NMR}(100 \mathrm{~Hz}$,

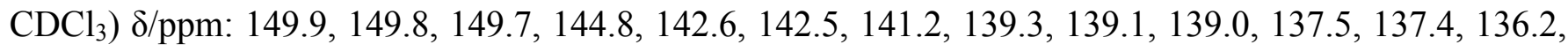
134.9, 132.0, 131.1, 130.6, 128.7, 127.6, 124.5, 120.6, 119.6, 118.8, 118.6, 118.2, 32.1, 31.9, 31.7, 31.6, 31.5, 31.4, 31.1, 29.7, 29.5, 29.4, 29.3, 27.2, 26.9, 25.2, 22.7, 22.6, 22.5, 21.7, 21.6, 21.5, 14.2, 14.1, 14.0. UV-Vis $\left(\mathrm{CH}_{2} \mathrm{Cl}_{2}\right), \lambda_{\max }(\mathrm{nm})$ (log $\left.\varepsilon\right): 293$ (4.64), 422 (5.40), 553 (4.72). EM ( $\left.m / z\right)$ (MALDI-TOF): calculated for $\mathrm{C}_{93} \mathrm{H}_{103} \mathrm{~N}_{5} \mathrm{O}_{2} \mathrm{~S}_{2} \mathrm{Zn}$ : 1449.68; found: 1449.94 .

\section{Computational details}

DFT Calculations were carried out using Gaussian 03 software package. ${ }^{3}$ For molecules 1, 2 and $\mathbf{3}$ treated here the semi-empirical Hamiltonian AM1 was first used for a few geometry optimization cycles to remove large geometry distortions. Molecules were then optimized at the B3LYP/3-21G* level of theory to refine the structure further with the B3LYP/6-31G* basis set. Molecules are visualized in the Figures using Jmol. ${ }^{4}$

\footnotetext{
${ }^{2}$ E. M. Barea, R. Caballero, Fabregat-Santiago, F.; P. De la Cruz, F. Langa, J. Bisquert, ChemPhysChem, 2010, 11, 245-250.

${ }^{3}$ Gaussian 03, Revision D.02, M. J. Frisch, G. W. Trucks, H. B. Schlegel, G. E. Scuseria, M. A. Robb, J. R. Cheeseman, J. A. Montgomery, Jr., T. Vreven, K. N. Kudin, J. C. Burant, J. M. Millam, S. S. Iyengar, J. Tomasi, V. Barone, B. Mennucci, M. Cossi, G. Scalmani, N. Rega, G. A. Petersson, H. Nakatsuji, M. Hada, M. Ehara, K. Toyota, R. Fukuda, J. Hasegawa, M. Ishida, T. Nakajima, Y. Honda, O. Kitao, H. Nakai, M. Klene, X. Li, J. E. Knox, H. P. Hratchian, J. B. Cross, V. Bakken, C. Adamo, J. Jaramillo, R. Gomperts, R. E. Stratmann, O. Yazyev, A. J. Austin, R. Cammi, C. Pomelli, J. W. Ochterski, P. Y. Ayala, K. Morokuma, G. A. Voth, P. Salvador, J. J. Dannenberg, V. G. Zakrzewski, S. Dapprich, A. D. Daniels, M. C. Strain, O. Farkas, D. K. Malick, A. D. Rabuck, K. Raghavachari, J. B. Foresman, J. V. Ortiz, Q. Cui, A. G. Baboul, S. Clifford, J. Cioslowski, B. B. Stefanov, G. Liu, A. Liashenko, P. Piskorz, I. Komaromi, R. L. Martin, D. J. Fox, T. Keith, M. A. AlLaham, C. Y. Peng, A. Nanayakkara, M. Challacombe, P. M. W. Gill, B. Johnson, W. Chen, M. W. Wong, C. Gonzalez, and J. A. Pople, Gaussian, Inc., Wallingford CT, 2004.

${ }^{4} \mathrm{Jmol}$ is an open-source Java viewer for chemical structures in 3D. http://www.jmol.org/
} 
Figure S1. ${ }^{1} \mathrm{H}$ NMR spectrum of dye $\mathbf{3}\left(\mathrm{CCl}_{3}\right)$

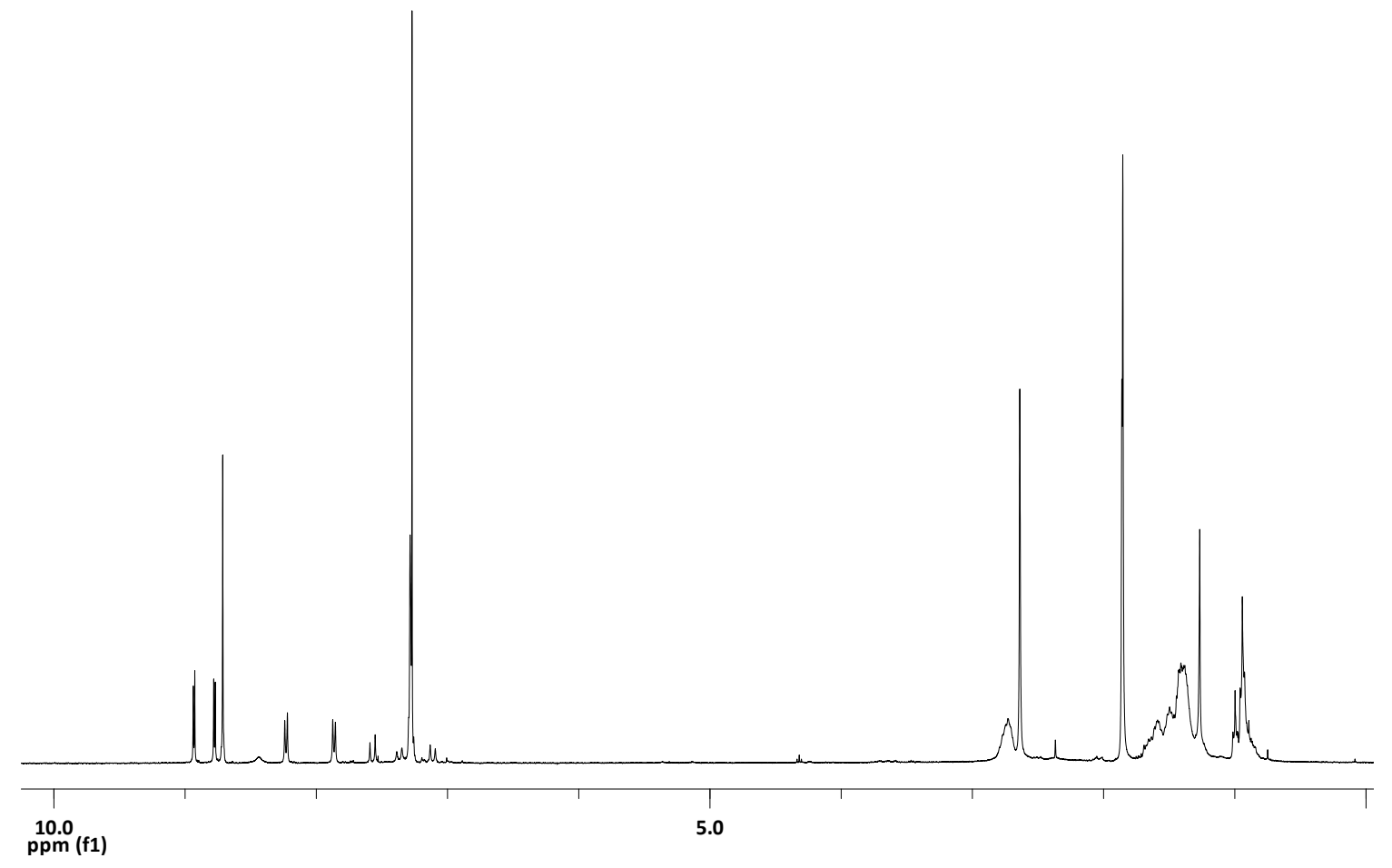


Figure S2. MALDI-TOF MS spectrum of Dye 1

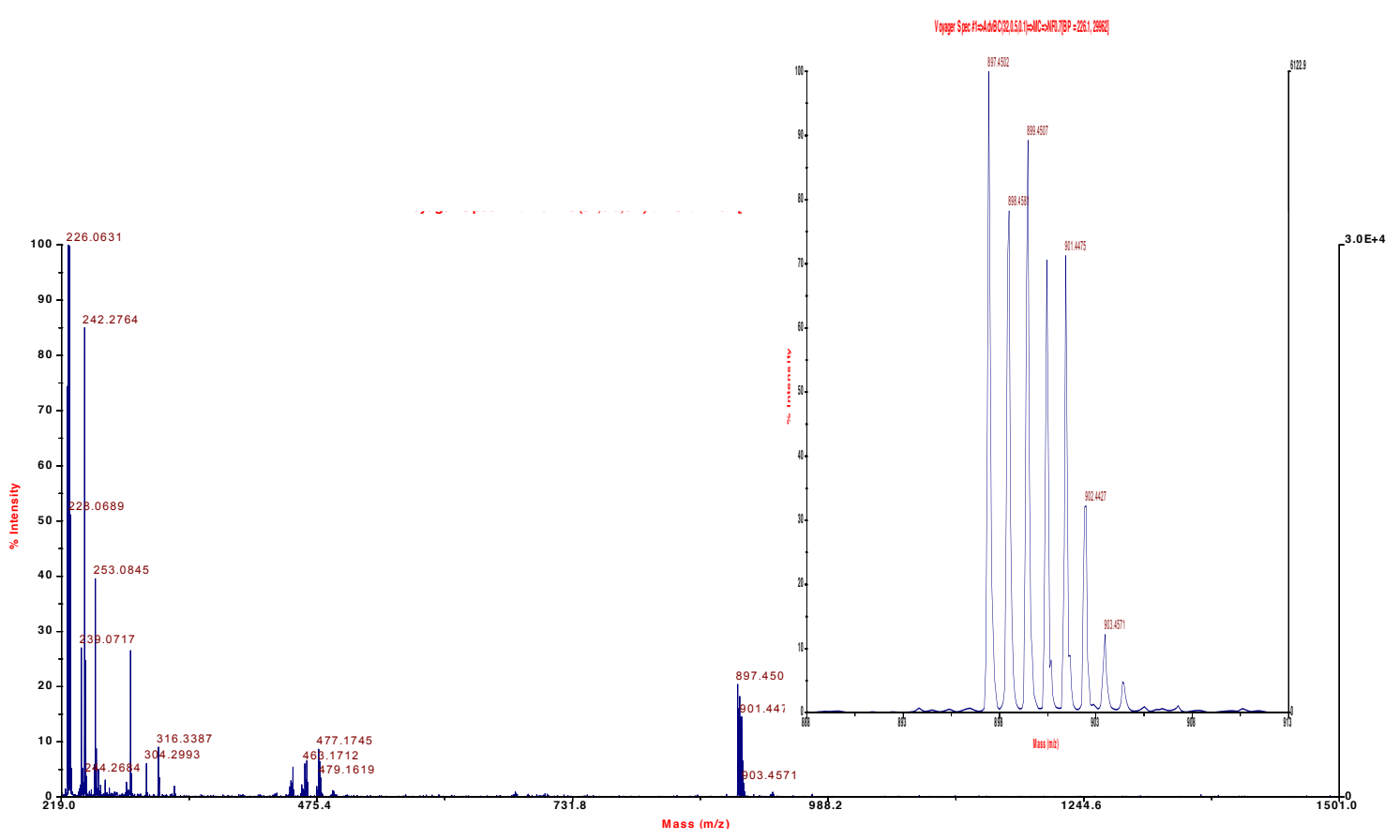


Figure S3. MALDI-TOF MS spectrum of Dye $\mathbf{3}$

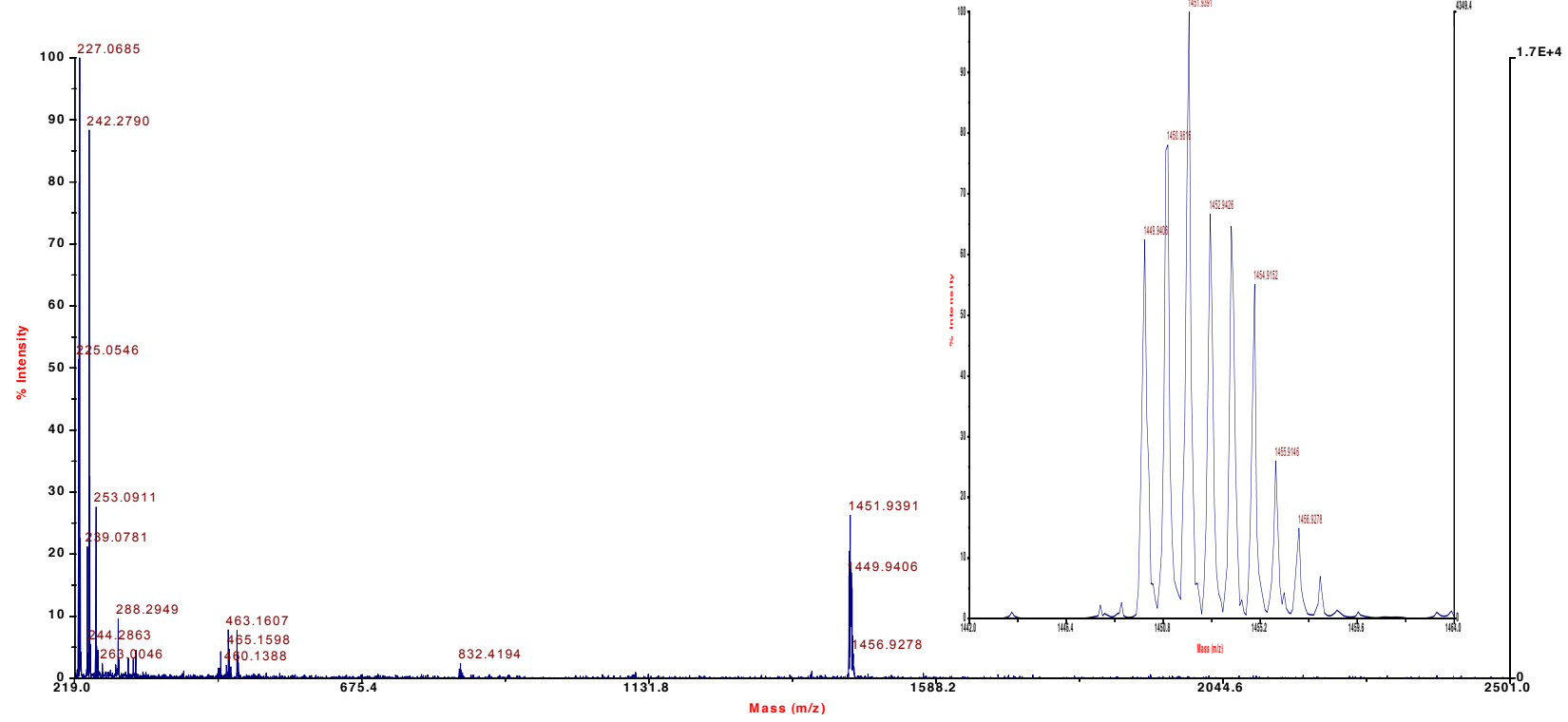


Figure S4. OSWV of dyes 1-3 (vs. $\mathrm{Ag} / \mathrm{AgNO}_{3}$ in o-DCB-acetonitrile (4:1) solution $\left(0.1 \mathrm{~mol} \mathrm{dm}^{-3}\right.$ $\mathrm{Bu}_{4} \mathrm{NClO}_{4}$ ). 1: dotted line, 2: dashed line; 3: solid line.

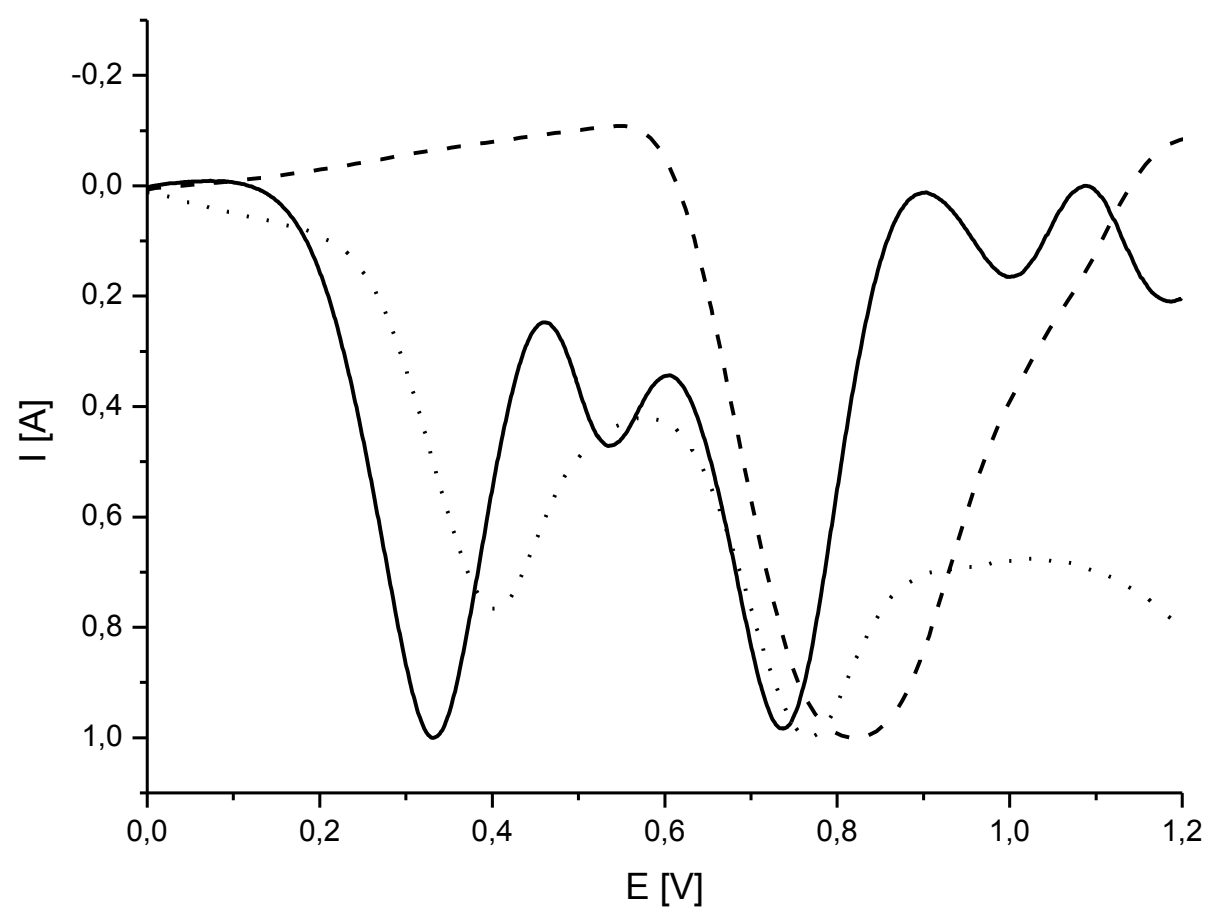


Fig. S5. Emission spectra of dyes in dichloromethane solutions: 1 (a) and 2 (b), (1: $\lambda_{\text {exc }}=422 \mathrm{~nm}$; 2 : $\lambda_{\text {exc }}$ $=488 \mathrm{~nm}$ ), in absence (solid line) and presence (dashed line) of $\mathrm{TiO}_{2}$.

(a)

(b)
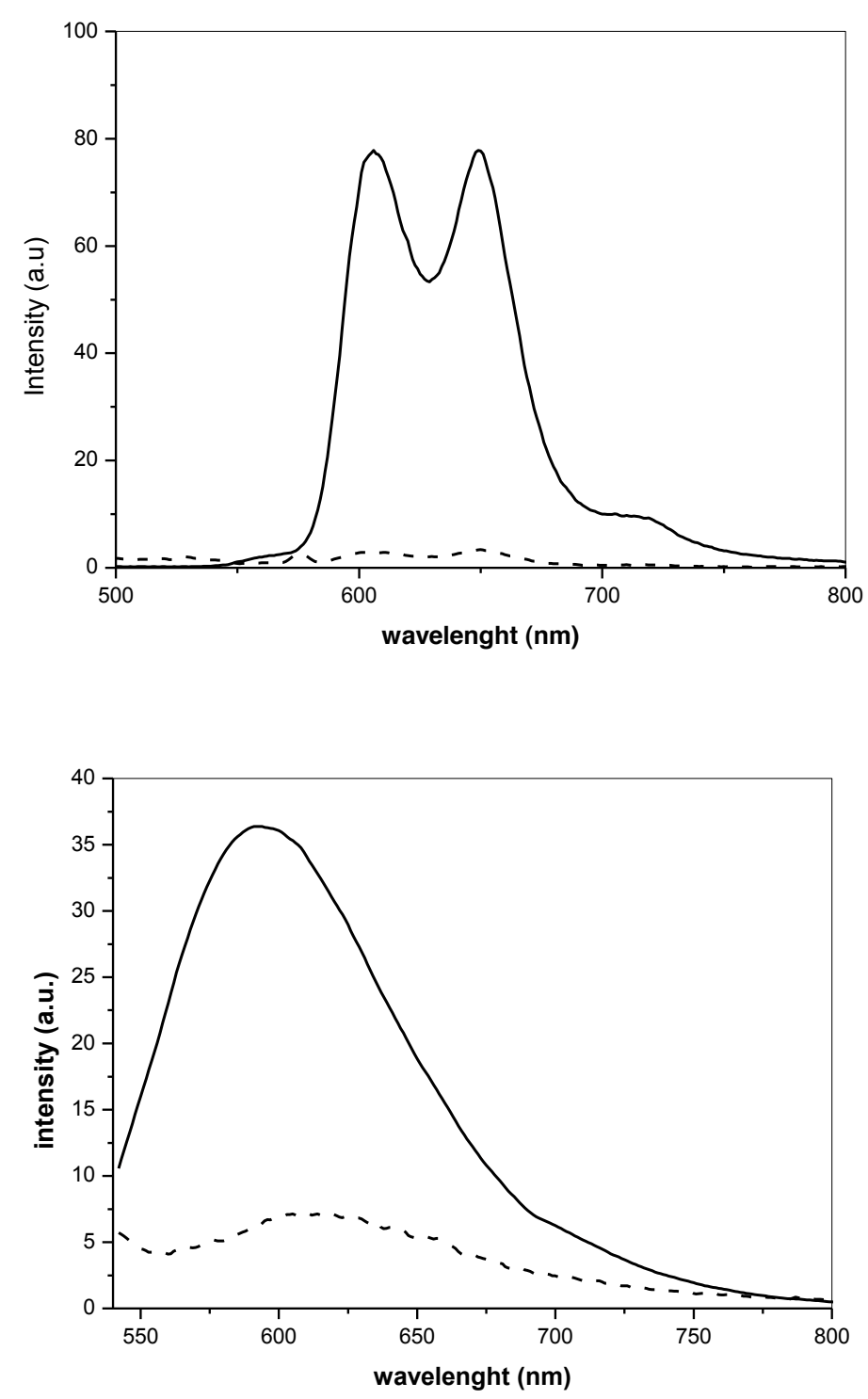


\section{Answersto Referees}

Manuscript number: cphc.201000958

MS-Type: Article

Title: "Triplication of the Photocurrent in Dye Solar Cells by Increasing the Elongation of the $\pi$ conjugation in Zn-Porphyrin Sensitizers"

Author(s): Eva M. Barea, Rubén Caballero, Leticia López-Arroyo, Antonio Guerrero, Pilar de la Cruz, Fernando Langa, and Juan Bisquert

In the revised version of the manuscript we have addressed all the referees' comments aiming to present the results in a clearer way. We acknowledge the referees for their suggestions. Below, find our response to referees' comments:

\section{Reviewer 1:}

The article "Triplication of the photocurrent in Zn-porphyrinsensitizers" by Barea et. al. reports the 3-fold enhancement of photocurrent by combining an oligothienylene-vinylene unit to a Zn-porphyrin. The device results reported here are based on a liquid electrolyte. The authors only report the device characterization without any further photophysical proofs to support the increase in photocurrent. To my opinion the results reported in this manuscript are not sufficient for publication in Chemphyschem.

The comments are as follows:

1. The HOMO/LUMO values and band gaps reported in the manuscript come from theoretical calculations, which to my opinion is not correct. Values determined from electrochemical measurements should also be included.

The electrochemical properties of the new dyes $\mathbf{1}$ and $\mathbf{3}$ were investigated by cyclic and OSWV voltammetries (vs. $\mathrm{Ag} / \mathrm{AgNO}_{3}$ in o-dichlorobenzene-acetonitrile (4:1) solution $\left(0.1 \mathrm{~mol} \mathrm{dm}^{-3} \mathrm{Bu}_{4} \mathrm{NClO}_{4}\right)$ and those of 2 were previously described. ${ }^{13}$ Both new dyes show reversible oxidation potentials at $0.40 \mathrm{~V}$ and $0.73 \mathrm{~V}$ (dye 1) and $0.33 \mathrm{~V}$ and $0.73 \mathrm{~V}$ (dye 3), in addition, dye 3 shows a non reversible oxidation potential at $0.53 \mathrm{~V}$ assigned to the oligothienylenevinylene bridge. ${ }^{13}$ The HOMO values (calculated with respect to ferrocene, HOMO:-4.8eV) were determined as $-5.01 \mathrm{eV}$ for dye $\mathbf{1}$ and $-5.03 \mathrm{eV}$ for dye $\mathbf{3}$.

2. The authors argued that the PL measurements support the efficiency of the charge injection but they have not provided any injection yield, which should be included in the manuscript with sufficient proof.

By the integration of the absorption spectra of Figure 5 with the solar spectrum, it is possible to calculate the maximum current that we can obtain from each dye, without any contribution like recombination or regeneration process that could take place during the DSC performance. For parent's dyes, $\mathbf{1}$ and $\mathbf{2}$, the maximum current that we can get is 11.8 and $11 \mathrm{~mA} / \mathrm{cm}^{2}$ respectively, and for the new dye $\mathbf{3}$ the maximum current is $18.2 \mathrm{~mA} / \mathrm{cm}^{2}$ that will be translate to a higher overall conversion efficiency. In the case of N719 dye, the current that we can get is very low due to experimental conditions used for measured the UV-vis spectra (short time deeping in dye solution, using a thin transparent titania film) and that is reflected in the overall conversion efficiency of the N719 DSC.

3. It is interesting to see that by the attachment of an oligothienylene unit to the porphyrin sensitizer the thin film absorption as well as IPCE increases dramatically, which resulted in an increase in current density. However, sufficient proof for electron injection efficiency, electron lifetime in the excited state should be provided to support the experimental results. 
About the measurements of electron life time in the excited state that could provided to support the experimental results we have not been able to carry out because is not possible to carry out this measurements in our labs.

4. The charge transfer transition due to the elongation of $\Pi$-conjugated system by DA-substituents is reported in several publications. The increase in photocurrent by the elongation of $\pi$-conjugation in porphyrin sensitizers was extensively studied and increased efficiencies have been reported. The authors are trying to proof their device performance from theoretical calculations using density functional theory (DFT). DFT calculations provide only the electronic structure (HOMO/LUMO distributions) of the molecule (and only accurately in the ground state), but cannot predict the increase in IPCE or energy conversion efficiency.

With the DFT calculations we only support the experimental dates. By theoretical calculations we determine that the addition of the oligothienylenevinylene unit to the Zn-porphyrin, transform it in a push -pull system. And the new dye as a push-pull system can increase the injection that is confirmed by the $I$ $V$ curve and also by the IPCE.

5. It is not a good example to compare 7719 with the Zn-porphyrin dye in thin films ( $6 \mathrm{\mu m})$ DSCs. In literature, high efficiencies of up to $4.8 \%$ in $3 \mathrm{microns} \mathrm{TiO} 2 \mathrm{films}$ have already been reported for the N719 dye. This manuscript reports higher efficiencies for the porphyrin dye (4.77\%) compared to N719 dye (4.27\%) which is not a good comparison and is misleading the readers.

Here is important to point out that we have used the optimal conditions to obtain the best performance with porphyrin dyes. We have not use the optimal fabrication conditions for N719. The films are made by a transparent titania films (6 microns), only two hours deeping in dye solution, and in the electrolyte composition there is not any ionic liquid. So using this fabrication conditions and in our lab, we obtain that efficiency. Nevertheless, using the optimal fabrication condition for N719 dye the higher efficiency that we can obtain is $7.2 \%$ (All this comments has been added to the revised version) 